Supplement of Biogeosciences, 16, 1705-1727, 2019

https://doi.org/10.5194/bg-16-1705-2019-supplement

(C) Author(s) 2019. This work is distributed under

the Creative Commons Attribution 4.0 License.

(c) (1)

Supplement of

\title{
Long-chain diols in settling particles in tropical oceans: insights into sources, seasonality and proxies
}

Marijke W. de Bar et al.

Correspondence to: Marijke W. de Bar (marijke.de.bar@nioz.nl)

The copyright of individual parts of the supplement might differ from the CC BY 4.0 License. 
2 We performed time-series spectral analysis on the Diol Index data from the Mozambique Channel to assess the influence of meso-scale eddies. Analyses were performed in MATLAB $®$. The two parts of

4 the Diol Index time series, i.e. the 2003-2007 and the 2008-2009 periods, were analysed both separately

5 and together. The data were linearly interpolated in time (to 21-day intervals for the 2003-2007 period,

6 and 17-day intervals for the 2008-2009 period) to adjust for disjunct sampling intervals or short gaps,

7 and detrended. A runs test for randomness (Gibbons \& Chakraborty, 2003) showed that for the second,

8 shorter time series (2008-2009) the null hypothesis - that the values in the series are in random order -

9 could not be rejected at the $5 \%$ significance level. The second series also lacked statistically significant

10 autocorrelation according to the Ljung-Box test (Ljung \& Box, 1978). Therefore, there was little point

11 in analysing the shorter 2008-2009 time series for periodicity. We performed a wavelet analysis to detect

12 transient features in the Mozambique Channel Diol Index 2003-2007 time series following the methods

13 of Torrence and Compo (1998; http://paos.colorado.edu/research/wavelets/) and using the Morlet

14 wavelet as mother wavelet. 

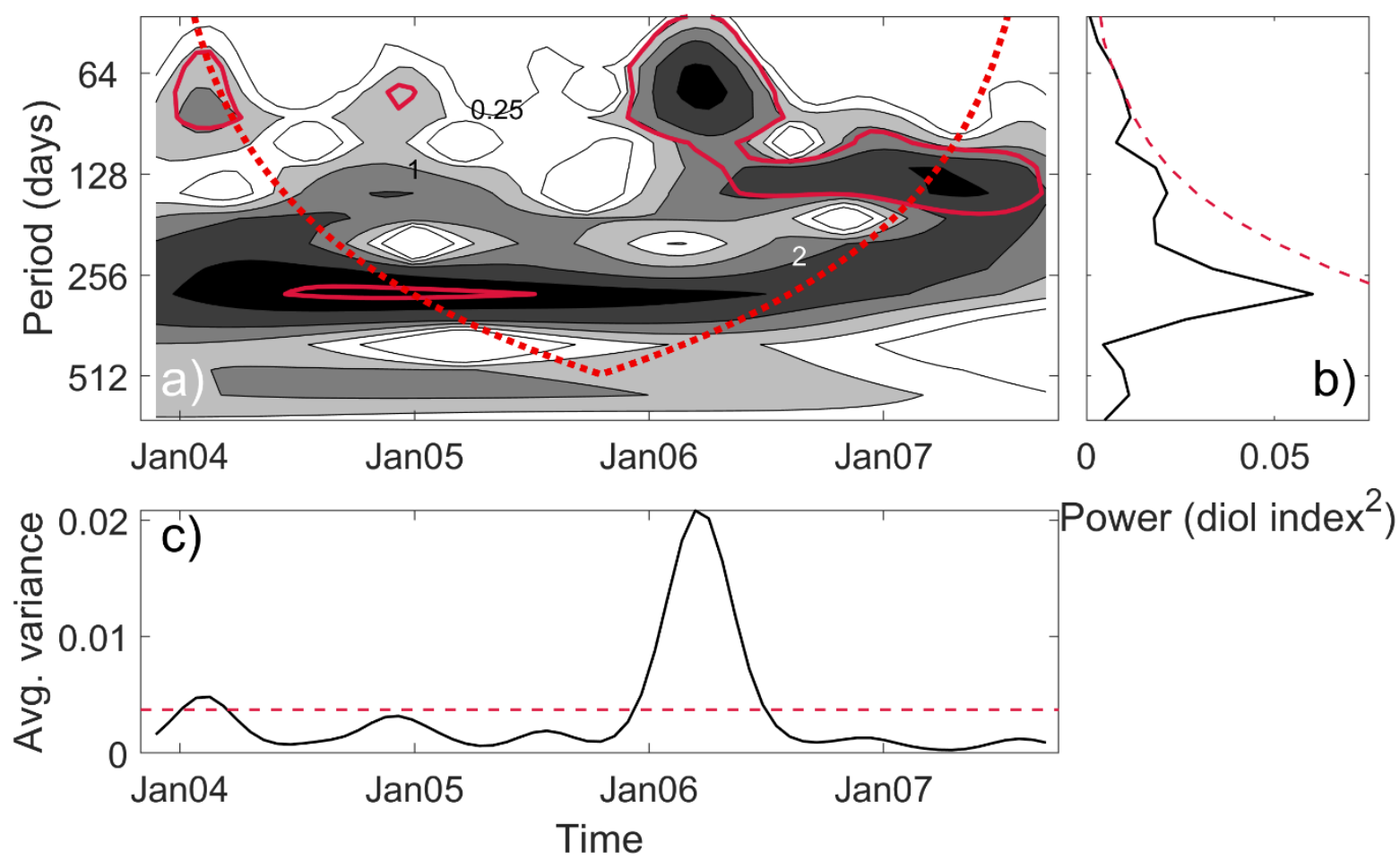

Fig. S1 a) The local wavelet power spectrum of the Diol Index in the sediment traps of the Mozambique Channel using the Morlet wavelet, normalized by the standard deviation. On the $x$-axis is time, and the $y$-axis shows the Fourier period in days. The shaded contours are at normalized variances of $0.25,0.5$, 1,2 , and 4 . The bold red contour encloses regions of greater than $95 \%$ confidence for a red-noise process with a lag-1 coefficient of 0.72 . Regions below the dotted red curve are where edge effects become important (Torrence and Compo, 1998). b) Global wavelet spectrum of Diol Index - the wavelet spectrum averaged in time over the whole time series. The red dashed line is the $95 \%$ confidence level. c) Wavelet power averaged over the range of scales from 42 to 90 days. The black line is the time series of the average variance within the 42-90-day range. The red dashed line is the $95 \%$ confidence level. 


\section{References}

35 Gibbons, J. D. and Chakraborty, S.: Nonparametric Statistical Inference, 4th Edn., Marcel Dekker Inc., 36 New York, 645 pp., ISBN 0-8247-4052-1, 2003.

37 Ljung, G. M. and Box, G. E.: On a measure of lack of fit in time series models, Biometrika, 65, 297$38 \quad 303,1978$

39 Torrence, C. and Compo, G. P.: A practical guide to wavelet analysis, B. Am. Meteorol. Soc., 79, 6140 78, https://doi.org/10.1175/1520-0477(1998)079<0061:APGTWA>2.0.CO;2, 1998. 